\title{
Towards Asia 2025: policy and technology imperatives. Summary of the main findings of the second international conference on Asian food security held in Singapore on 21-22 August 2014
}

\author{
Paul Teng • Mely Caballero-Anthony • Jonatan Lassa • \\ Tamara Nair
}

Received: 14 December 2014 / Accepted: 18 December 2014 /Published online: 8 January 2015

(C) The Author(s) 2015. This article is published with open access at Springerlink.com

The ICAFS in 2014 was held with the following objectives:

- To suggest recommendations that contribute towards enhancing food security at the national and regional levels, and identify clear policy directions and interventions to guide efforts towards food security.

- To provide concrete and actionable policy recommendations attuned to the new realities of food security challenges as Asia approaches 2025.

- To identify ways in which Asia could position itself to maximise the full benefits of its connectivity and build on its comparative advantage within and vis-à-vis other regions.

ICAFS brought together experts from the public, private, civil society and academic sectors to address the above objectives. The time-horizon of 2025 was chosen for a number of reasons. It represents 10 years after the end of the Millennium Development Goals and the initiation of the Association of South-East Asian Nations (ASEAN) Economic Community. From a national planning standpoint, a decade commonly represents a good medium-term time frame for policies to be formulated and enacted. On a regional level, ASEAN's post 2015 agenda will also be using a 10 year time-frame for planning. The International Food Policy Research Institute

P. Teng $(\varangle) \cdot$ M. Caballero-Anthony $\cdot \mathrm{J}$. Lassa $\cdot$ T. Nair Centre for Non-Traditional Security (NTS) Studies, S. Rajaratnam School of International Studies, Nanyang Technological University, Singapore, Singapore

e-mail: paul.teng@nie.edu.sg
(IFPRI) has also chosen 2025 as the year when the world should aim to eradicate hunger and malnutrition.

The First Session highlighted the trends and challenges to food security from the present to 2025 for Asia but in a global context. Session 2 highlighted the food supply-demand situation and opportunities for improving productivity growth and supply chains. Session 3 addressed the issues of market integration and trade facilitation, recognizing that regional integration and food trade are important means for sustaining food security by increasing economic access to food. Session 4 dealt with options for financing and investing in agricultural innovation and technology. In session 5 different sectors shared their respective contributions to an integrated approach to food security for Asia by 2025. The conference ended with a keynote address by a representative of the Asian Development Bank (ADB) on the way forward to cooperate regionally to ensure food security for all in Asia.

\section{Asia 2025 - trends and challenges to food security}

Ending hunger and undernutrition in Asia by 2025: what will it take?

Asia had about $60 \%$ of the world's hungry during the period of 2011 to 2013. The social costs associated with hunger and malnutrition come in the form of declining human development and dignity. Therefore, eradication of hunger and malnutrition in Asia must be made a top priority by 2025 and can be achieved if the rates of hunger and stunting drop respectively, at 4 and $9 \%$ annually. One way of doing this is for Asia 
to emulate existing initiatives practised in other regions such as the Zero Hunger Challenge, End Hunger in Africa, and Rio +20 , all of which aim towards the eradication of hunger. The opportunities for Asia to liberate itself from hunger and malnutrition come from its rapid economic growth, relatively high crop productivity, agriculture expansion, and transformation of Asia's agrifood system, the latter being influenced by rapid urbanisation, diet change, food market transformation, rise of rural non-farm labour markets, agricultural technology and change in farm size.

Financing agricultural innovation and technology - farmers' perspective

On the food supply side, Asia is facing natural resource constraints that result from competitive use of land and water, land conversion, increase in degraded soil and polluted water, and rising costs of land and water. Global climate change may modify the frequency and/or cycle of adverse weather and very likely lead to the reduction of crop yields as a whole, affecting food access, utilisation and price stability. Uneven ownership of land and natural capital, technology, and unequal food production and availability across regions and countries further exacerbate the stability of food supply. Established knowledge suggests that high costs of labour, fertilisers, and chemicals, as well as corruption in government, further jeopardise smallholder farmers' enterprises. In addition, agricultural investment is needed to support smallholder farmers, enhance their income and productivity, and increase food availability and accessibility in the market. Furthermore, safeguarding soil from erosion, preserving water, and conserving land and biodiversity, will also help farmers to increase and maintain productivity.

Food security challenges in developing Asian countries: the case of Indonesia

In the case of Indonesia, malnourishment among children needs greater improvement as it stood at $19.6 \%$ in 2013 compared to $24.5 \%$ in $2005,18.4 \%$ in 2007 , and $17.9 \%$ in 2010 . High demand for food is attributed to the large population size of 252 million (in 2014). Consistent increase in population growth rate combined with rapid urbanization (estimated to be at $60 \%$ of the total population in 2025) will further increase not only demand for food but also for different types of food. Women participation in the labour force, which stands at $36.4 \%$ of total employment, escalates the "eat-out" rate and heightens demand for processed food. On the food demand side, transformation of food consumption patterns has resulted in increasing demands for certain types of foods such as those with higher protein and vitamin content. City lifestyles that come with urbanisation increase demands for processed food. Food policies need to take into account the shift from food consumption based on quantity toward diverse, nutritious, balanced, and safe consumption by promoting food processing technology, nutrition, and food safety standards.

The post 2015 agenda on hunger and malnutrition

As the end of the target year of 2015 for the Millennium Development Goals (MDGs) to be met is approaching, countries are seeking to intensify efforts aimed at ending poverty. There are two successive processes that countries are negotiating for the post-2015 development agenda, and these are the Open Working Group (OWG) on Sustainable Development Goals (SDGs) and the Post-2015 UN Agenda negotiations. Food security has been regarded as an important goal in both processes. However, in the draft report of the Open Working Group, 'food security' is replaced by 'ending hunger'. This may not be conducive for the fight against hunger and malnutrition as food security would be a more inclusive discourse. It is important that the food security language be brought back to the final report of the Opening Working Group. Gaps in policy implementation should also be reduced.

\section{Supply and demand - improving productivity growth and supply chains}

Food supply and demand in Asia: challenges

and opportunities for policy and technology interventions

Food demand in Asia will be driven by population growth, urbanization, income growth, expansion of biofuel use and mitigation of greenhouse gas emission. On the other hand, food supply will be influenced by water and land scarcity, climate change, investment in agricultural research and science and technology policies. Given that technologies can significantly improve food production, countries should accelerate investment in research and development in agricultural technologies, promote complementary policies and investment, and reform economic policies. With regard to investment in research and development, it is important that attention be paid to technologies for crop and livestock breeding that increase yields and enhance the ability of crops and livestock to resist diseases, drought, heat and salinity. Policy reforms in domestic regulations and trade are also essential to facilitate the application of new agricultural technologies and encourage free and open trade. 
Modernizing food supply chains as an integral necessity to assure food security

Southeast Asian countries are active in food trade. Thailand is a major exporter of rice; the Philippines dominates the supply of banana; Indonesia exports shrimp and prawns. However, current supply chains in Southeast Asia for commodities such as rice, fruits and seafood have not been sufficiently efficient. Several Southeast Asian countries have big surpluses of rice and there is potential for rice trade within the region as well as across regions. Regional supply chains are constrained by lack of efficiency and lack of effectiveness. Efficient border management ensures timeliness of delivery and this is crucial for commodities such as meat and seafood. Infrastructure also has a critical role in logistics. For instance, congestion may increase delivery costs and cause delay. Tracking and tracing of commodities are also important aspects of the supply chains. To improve the effectiveness of regional supply chains, it is necessary to simplify the procedures for port handling and border control, reduce the costs in domestic transport and cold chains, ensure food safety, enhance infrastructure and review legislations to facilitate the flow of commodities. In this regard, the implementation of new procedures under the ASEAN Economic Community (AEC) initiative could contribute to improving intra-regional trade.

\section{The role of the private sector}

Recent history has shown that technology plays an important role in food security as it creates better inputs that increase productivity consistently. In this regard, the private sector as technology developers and providers connect people, land and technology and may offer better solutions, support rural economies, and resource use efficiency. Using technology over a span of a decade since 1990, Vietnam has doubled its rice production, exported seven times as much, and has become the world's largest rice exporter in recent years. In the Philippines, genetically modified corn has resulted in lower production costs, higher productivity, and a safer environment, and has enabled the Philippines to become self-sufficient in corn and even export a small surplus. Private sector players in the food industry should continue their commitment to making crops more efficient by significantly increasing the average productivity of the world's major crops without using more land, water or inputs, rescuing more farmland by improving the fertility of millions of hectares of farmland on the brink of degradation, helping biodiversity flourish by enhancing biodiversity of farmland, empowering smallholders and enabling farmers to increase agricultural productivity. In the future, the potential of GMO (genetically-modified organism) technology should be explored to ensure and increase food production.

The role of scientific innovations

There has been a variety of scientific breakthroughs available for improving food security, such as those from genetics, molecular biology, plant physiology, and remote sensing. Innovations should contribute to food security through its three components - availability, access and consumption. Agricultural technologies enhance availability of food through higher yield and more efficient use of food. There are two ways to increase crop productivity - to close the gap between the actual yield and potential yield and to increase the potential yield. Because the yield of crops is affected by a variety of factors, such as weeds, pests, diseases, pollution and availability of water, the actual yield is always lower than the theoretical maximum yield. Closing the gap between the two will lead to higher outputs. Developing countries in Africa and Asia have considerable potential to increase output through this approach. Climate change poses another problem to agricultural production and climate smart agriculture that applies technological innovations is proposed to improve the efficiency and resilience of the agricultural system, adapt it to the changing environment and mitigate the impacts of climate change. Water management, eco-efficiency, precision agriculture, and breeding are areas open for technological innovations. Another way to improve availability is to avoid food losses and waste and create alternative protein sources. New technologies improve the structuring of food, diversify the sources of protein and prolong food preservation.

\section{Market integration, trade and economic access to food}

Regional integration and economic access to food

Food trade can be one effective way to achieve food security. There is a paradox where the most food-secure richer nations are the ones with deficient food production capacity while the food-insecure poorer member states have the most abundant agricultural resources but also are most vulnerable to price shocks. This phenomenon is indicative of the fact that domestic food production to give self-sufficiency does not necessarily equate to food security. This further highlights the importance of economic access as one of the key dimensions of food security. The challenge for the Asian region is to increase economic access to food to improve food security. Through greater regional economic integration, efforts such as the AEC 2015, the ASEAN region stands to gain through higher growth and increase in per capita GDP. The AEC 2015 
agenda, which includes tariff reduction, enhanced trade facilitation, reduction in barriers to trade, among others, aims to accelerate economic growth and development. Despite significant progress that has been made on the AEC 2015 front to improve food security, much remains to be done.

Trade facilitation and logistics service liberalization

The key elements of trade facilitation include trade and customs regulation, trade documentation, customs clearance, trade enforcement, trade finance and infrastructure development. The ASEAN region aims to improve trade facilitation because it brings forth large potential savings due to reduction of transaction costs. Bureaucratic processes in the import and export of agricultural and food products increases uncertainties and impedes trade across the supply chains. This is especially disadvantageous because food requires stability and reliability across the supply chains both within and between countries. Lack of automation and insignificant use of information technology, lack of inter-agency coordination and cooperation among customs and other government agencies cause inefficiencies. Addressing these barriers to trade and improving trade liberalization are included in the AEC 2015 agenda. The move towards greater integration will also provide substantial improvement in the facilitation for crossborder trade within the Southeast Asia region, which will enhance physical access to food and therefore improves food security. One specific step towards this goal is the implementation of 'National Single Window' systems, which accelerate trade procedures and reduce corruption.

\section{China as a key regional player in food security}

China's population growth per se will have limited impact on global food demand. What are of more oconcern are increasing urbanisation and income growth, which could influence food consumption patterns. China will also benefit from investments in farming technology and agricultural research and development. As for key commodities, projections show that China will achieve self-sufficiency in rice and wheat but demand for maize and soybean is expected to rise. Increments in demand for maize and soybean will be compensated through existing trading partners in North and South America, easing pressure on food imports by other countries within the region. Projections also indicate that Asia will gain from the demand surge in palm oil and tropical products from China.

India as a key regional player in food security

India is the only country in the region to have legislated food security but this has raised questions and increased debate as to its impact on the domestic economy and food security. India's National Food Security Act (NFSA) 2013 generally seeks to provide food and nutritional security by means of providing a sufficient amount of food at affordable prices to each household. The act aims to subsidize about $75 \%$ of the rural and $50 \%$ of the urban population's need of fixed amounts of food grains per month. While the objective is greatly applauded, the act has been plagued with much criticism and politically charged debate. While NFSA addresses the country's food security and growing hunger and malnutrition problems, the act remains a directive principle and does not promote the fundamental right to adequate food.

\section{Financing and investing in agricultural innovation and technology}

Investing in agricultural research and development

The International Rice Research Institute (IRRI) showed that for every US\$1 invested, at least US\$9 worth of additional food is produced in developing countries. Research by IRRI for instance, has delivered benefits of US $\$ 1.46$ billion per year and boosted annual rice yields by an average of $11.2 \%$ in Southeast Asia during 1985-2009. Unfortunately, international funding for agricultural development as a whole, and more specifically agriculture and rice research, have gone through highs and lows over the past 40 years. Financial support, in the form of official development assistance (ODA), to $R \& D$ is lacking. ODA to agriculture, particularly from major donors such as the EU, USA and Japan, has fallen over time. International resource flows emanating from loans, portfolio equity, remittances and foreign direct investments have grown rapidly over the years, while ODA has remained stagnant. ODA to agriculture as a share of total ODA has been declining, from $8.5 \%$ in 1980 to $2 \%$ in 2006 . Moreover, most of the ODA funds for agriculture are already allocated to food aid, health and debt relief. While the world has been facing new challenges, the growth in global rice yield has significantly slowed due to worsening scarcity of land, labour and water resources. Furthermore, climate change is expected to reduce annual grain production. Increasing temperature, rising sea level, changes in rainfall pattern and weather hazards could destroy crops and farmlands. Therefore, in order to ensure food and nutrition security for all today and in the future, it is crucial to invest substantially in agricultural research and development.

The role of private equity

The Food and Agriculture Organisation (FAO) estimated that in order to achieve global food security, the developing world would require US\$ 83 billion in investment annually, up to 2050. Current investment stands at US\$ 55 billion annually, 
with an annual shortfall of US\$ 28 billion. The majority of this will likely be met by the private sector with the balance by government. Possible areas of private sector intervention include the food supply chain, storage facilities, food production, marketing and microfinancing. But many food and agriculture value chains are not represented in the region's stock exchanges and where present, only amount to about $5 \%$ of market capitalisation. Private equity is viewed as a highly efficacious mode of accessing these value chain opportunities in Asia due to prevailing levels of market development and specific value chain characteristics.

Insurance and microfinancing

Poor farmers are the most vulnerable to multiple risks and they need insurance. Insurance therefore can help farmers avoid sale of productive assets and reduce their reliance on government post-disaster aid. Insurance enables investments to flow into the agricultural sector. It allows farmers to invest in other crops, fertilizers, machinery, and irrigation and reduces risks for investors. Insurance also provides access to credit. It can be used as collateral for credit; there is no need to pledge other assets. However, getting insurance, particularly paying the premiums, is already too expensive and complicated for farmers. Governments therefore can help farmers and intervene through subsidies which can be used to pay farmers' insurance premiums. Microfinancing is also crucial to provide the farmers with the seed money which they can use to either innovate or rebuild their livelihoods after a disaster.

\section{Charting an integrative approach for Asia towards 2025}

Rice will continue to be the key to Asia's food secure future

Rice is unsurpassed as the main staple food of Asia. A clear major portion of rice is both produced and consumed in Asia and it is often considered the most strategic crop for most Asian countries. Given the prevalence of rice in the Asian diet, the future of Asia's food security is inherently tied and linked to this crop. In order to be able to provide enough food in the future, a second green revolution will be required. Science and R\&D are going to be of critical importance in achieving this. However, they need to answer the challenges arising from biotic and abiotic stress (including climate change) as well as the human dimension of production and supply (e.g., institutions, technology, decision making, trade policy, etc.). A rice secure Asia would go a long way in guaranteeing a food secure Asia in the future.
Indexing, benchmarking and better monitoring for food and nutrition security

Food security is a complex and dynamic issue which involves multiple dimensions, disciplines, actors, processes and systems. It is thus often extremely difficult to assess the food security situation in a holistic manner taking into consideration the availability, accessibility, and utilisation aspects. An index that accounts for all these dimensions which impact food security would help in establishing a baseline for comparison of food security situations between various countries or sub-regions. It could also be useful in understanding and comparing the level/state of food security in the same country over a period of time or from one year to another. Food loss and waste also need to be mainstreamed via systematic monitoring tools and metrics. This could help in better guiding investment and R\&D in areas and sectors that need the most attention. Indexing and benchmarking of food security will need to factor in the natural environment, health, macroeconomic policies, trade policies, tariffs, political stability as well as emergencies and natural disasters.

Reducing food insecurity during and after calamities and disasters

Other than making the physical stock of food available in disaster areas, countries and agencies dealing with the aftermath and food insecurity of affected people will also need to consider the most effective modalities in addressing the issue. This involves decisions as to whether providing physical food aid, food vouchers or cash transfers to the people is something that will need to be assessed and put into practice. Ideally, provision for all options should be put in place, so that there is the possibility of any of these strategies being used as and when deemed useful or necessary. Secondly, a pro-active and ex-ante planning approach is encouraged instead of reactive responses. The strategy includes building up and maintaining small strategic stockpiles of food in regions prone to or deemed vulnerable to disasters and calamities. Governments and policymakers should give more attention to improve emergency food reserves especially in vulnerable and isolated areas.

\section{The Way forward - regional cooperation for food security}

A range of food security-related issues were shared during ICAFS but five emerging challenges are highlighted that impact the future of food security in the region. The concept of food requires rethinking because agricultural policies have failed to take into account the changing patterns of food consumption and the evolving components of food. In the past, food security mainly connoted required caloric intake but 
today the concept spans nutritional concerns and safety issues. It is also important to note the link between food and safe production, for instance, the use of pesticides on food crops must be closely monitored. Furthermore, based on an Asian Development Bank (ADB) study, aggregate GDP in the Asian region will account for more than half (52\%) of the world's GDP. This growth forecast is based on the fact that about 3 billion Asians will move up to the middle class. The changing affluence and lifestyles of the population will also bring about corresponding changes in patterns of food consumption. Consequently this points to a range of different issues and scenarios in food security that will need to be addressed by the region.

\section{Managing the impact of climate change}

The current use of water and land resources has already surpassed sustainable levels. Such environmental degradation will trigger substantial losses in food supply capacity by 2050 . Climate change and natural disasters will also adversely affect developing countries in the region; in particular, a significant percentage of irrigated crops. This implies that, additional to another green revolution, further investments in climate change adaptation and mitigation will be needed to address widespread effects of environmental vagaries on food security.

\section{Adopting a new business model}

It is also important for the future of food security to adopt a new business model for agriculture. With reference to the structural transformation of developed economies, the trajectory commonly shifts from agriculture to industry then to the services sector. Such transformations bring about a corresponding increase in income. However, in the Asia-Pacific region, around $40 \%$ of labour remains dependent on the agriculture sector with the relatively marginal contribution of $10 \%$ to GDP. It is thus crucial to develop a business model that would increase productivity in the agriculture sector. This new model must also take into account rural-urban movements by $2030-2040$. Such movements result in rural farm populations and potential agriculture labour reductions. The decline in farming populations also relates to the low aspirational value of farming. It is thus important to create opportunities that will attract a younger labour force into the agriculture sector. Increasing farming productivity and promoting agribusiness will generate more commercial opportunities for farmers. Given the efforts toward market integration in the ASEAN Economic Community, there is huge potential to create lucrative business opportunities in agriculture.
Improving supply chain

Equally significant for the future for food security are the segments beyond the farm gate. These post farm gate segments of the food value chain have been effective in generating value additions for the agriculture sector. As such it will be beneficial to increase investments to upgrade related food value chain infrastructure such as food storage, railways, power grids, mobile phone communication, and logistics distribution. To transform productivity and enhance world food systems, it is also essential to minimize food losses across the supply chain, which will require further investment in post-harvest operations.

In order to effectively address future food security challenges, there is a need to drastically transform the entire food supply system from 'farm to fork'. This new system will have to be defined by higher productivity, deeper integration, higher efficiency and better resilience to shocks. Innovation will prove to be of critical importance to successfully attaining such transformations.

Logistics innovation backed by institutional capacity building is essential to aggregate and manage the quality of products generated by smallholders. This is particularly beneficial for the Asian region because $90 \%$ of the farms are cultivated by smallholder farmers. They produce the bulk of food distributed across the value chains. Their successful integration into the commercial food value chain will be key to improving food security. Logistics should also be adapted to the needs and prevailing conditions of the market and consumers. For instance it has become essential for emerging value chains for high value crops that cater for urban elites to involve more sophisticated logistics arrangements and vertical integration of value chains.

\section{Investing in innovative technology and infrastructure}

Developing and disseminating innovative technologies will be instrumental in increasing crop production per hectare, per litre of water used, energy per kilowatt and per farmer hours worked. These can be achieved through more extensive $R \& D$, hence the need for greater support and funding for agro-food research. One of the means to increase investments in agricultural $R \& D$ is through partnerships involving the public and private sectors.

There is also a need for more infrastructure investment, which is currently the ADB's area of focus. The Asian region will have to upgrade infrastructure to integrate fragmented markets, reduce transaction costs and disseminate resource saving technology across the value chain. In Asia, the majority of agricultural markets are not fully integrated, which often stems from a lack of interest. This is why investment efforts need to be focused on developing storage technologies, market infrastructure, cold chains, and processing facilities, all of which are essential components that link different markets. Improving infrastructure along with logistics services and institutional capacity will enhance physical access to food. 
Fundamental investments in agriculture are required for successful upgrading of food value chains. Agricultural investment is a significant area of strength for multilateral agencies like the ADB to consider. However, in recent years it has become a challenge to find investment-worthy projects. In Asia, the access to formal financing for smallholder farmers remains a key constraint. Smallholders have often been limited to microfinance loans that provide them with too small an amount to address their needs. Governments should look more closely to creating agricultural policies that would incentivize poor smallholder farmers beyond micro-finance. Collaboration and partnership from public and private sectors to support farmers and agriculture in general should also be further explored.

From a development angle, good policy and regulation are imperative. The region particularly needs an efficient regulating environment for developing agricultural technology and enabling policies to provide adequate incentives for sustainable business development. Policies will also be crucial in improving water and energy resource use, enhancing trade, and correcting market distortions. There is a need to ensure that agricultural policies and regulations adequately address evolving issues in relation to food production, storage and consumption.

\section{Creating an enabling policy and regulatory environment}

Enabling policy and regulatory environments are a crucial part of regional trade and cooperation. Bottlenecks within crossborder trade are major constraints in the region and these will have grave repercussions on food trade. It is important to harmonize policies and regulations and ensure transparency. One example is provision of food safety standards and quality assurance among regional food programs. Overall, more support is needed for the improvement of food security in the region.

The official conference report is available on line at http:// www.rsis.edu.sg/nts/.

Acknowledgments ICAFS 2014 was made possible through financial support provided by the National Security Coordinating Secretariat and Ministry of National Development, Singapore, Syngenta Company, and the Economic Research Institute for ASEAN and East Asia, Indonesia. Knowledge partners included IFPRI, IRRI, CropLife Asia, Food Industry Asia, Syngenta Company, the International Service for the Acquisition of Agribiotechnology Applications, the Business Council for Sustainable Development Singapore and the Southeast Asian Regional Center for Graduate Study and Research in Agriculture. The ICAFS programme was developed under the guidance of an International Advisory Committee consisting of Dr. Shenggen Fan (IFPRI); Dr. Ponciano Intal (Economic Research Institute for ASEAN and East Asia), Dr. Achmad Suryana (formerly Indonesian Agency for Food Security), Dr. Bev Postma (Food Industry Asia), Dr. Jikun Huang (Chinese Centre for Agricultural Policy), Mr. Marcel van Doremaele (Rabobank Singapore), Dr. Maripaz (WorldFish Center), Mr. Melvin Chow (Agri-Food \& Veterinary Authority, Singapore), Dr. Robert Holmer (formerly Asian Vegetable Research and Development Center) and Dr. Tan Siang Hee (CROPLIFE Asia). Organization of the meeting was ably assisted by the following research staff of the Centre for Non-Traditional Security Studies, S. Rajaratnam School of International Studies - Cheryl Lim, Margaret Sembiring, Maxim Shreshta, Hia Mooi Huang and Jurise Oliveros (National Institute of Education, Singapore).

Open Access This article is distributed under the terms of the Creative Commons Attribution License which permits any use, distribution, and reproduction in any medium, provided the original author(s) and the source are credited. 